\title{
Clinical and Epidemiological Features of Patients with Chronic Hepatitis C Co-Infected with HIV
}

\author{
Eduardo Lorens Braga ${ }^{1,2}$, André Castro Lyra ${ }^{1,2}$, \\ Fabrizio Ney-Oliveira ${ }^{1}$, Lourianne Nascimento ${ }^{1}$, \\ Adriano Silva ${ }^{3}$, Carlos Brites ${ }^{3}$, Rosicreuza Marbak ${ }^{1,2}$ \\ and Luiz Guilherme Costa Lyra ${ }^{1,2}$, Manuel L. Ribeiro \\ Neto $^{4}$ and Koonj Asvin Shah ${ }^{5}$
}

\author{
${ }^{1}$ Department of Medicine, Gastro-Hepatology Service, Federal \\ University of Bahia; ${ }^{2}$ Gastro-Hepatology Service, São Rafael \\ Hospital/Monte Tabor Foundation; ${ }^{3}$ Department of Medicine, \\ Infectious Disease Service, Federal University of Bahia; \\ Salvador, BA, Brazil; ${ }^{4}$ Jackson memorial Hospital, University of \\ Miami, Florida; ${ }^{5}$ Health Science Center, University of Texa; USA
}

\begin{abstract}
Co-infection with hepatitis C virus (HCV) and human immunodeficiency virus (HIV) is increasingly common and affects the clinical course of chronic hepatitis $\mathrm{C}$. Highly active antiretroviral therapy has improved the life expectancy of HIV infected patients, but, by extending survival, it permits the development of HCV cirrhosis. This study tried to evaluate clinical and epidemiological features of patients with chronic hepatitis C co-infected with HIV. We evaluated 134 HCV-infected patients: i) group A - 65 co-infected HCV/HIV patients, ii) group B - 69 mono-infected HCV patients. The impact of HIV infection on HCV liver disease was analyzed using Child's score, ultrasound findings and liver histology. Patients were subjected to HCV genotyping and anti-HBs dosage. Patients mean age was 42.4 years $( \pm 9.1)$ and $97(72.4 \%)$ were males. Injected drug use and homo/bisexual practice were more frequently encountered in the co-infected group: $68.3 \%$ and $78.0 \%$, respectively. Antibodies against hepatitis B virus (anti-HBs) were found in only $38.1 \%$ of the patients $(66.7 \%$ group Ax $33.3 \%$ group B). Ten out of 14 individuals (71.4\%) who had liver disease (Child B or C) and 25 out of 34 (73.5\%) who showed ultrasound evidence of chronic liver disease were in the co-infection group. $\mathrm{HCV}$ genotype-2/3 was more frequently encountered in co-infected patients (36.9\% group A vs. $21.8 \%$ group B). Conclusions: a) HIV infection seems to adversely affect the clinical course of chronic hepatitis $C$, b) injected drug use, bi/homosexual practice and genotype-2/3 were more frequently encountered in co-infected patients, c) immunization against HBV should be encouraged in these patients.
\end{abstract}

Key Words: Hepatitis C, HIV, co-infection, clinical course, HCV genotype.

Co-infection between hepatitis C virus (HCV) and immunodeficiency virus (HIV) is a serious clinical condition. Worldwide, over $3 \%$ of the population has chronic hepatitis $\mathrm{C}$, the leading cause of progressive liver disease and cirrhosis [1]. HIV-positive patients are at high risk for infection by HCV, with an estimated prevalence of 30\%-35\%[2]. In the population of drug users, the prevalence of $\mathrm{HCV}$ can be higher than $80 \%[3,4]$.

Progression to cirrhosis in chronic HCV-infected individuals can be precipitated by some "co-factors", such as alcohol abuse and co-infection with HIV [5,6]. End-stage liver disease is one of the most important causes of hospital admissions and death in HIV-infected patients [7], in whom the severity of hepatocellular necrosis, portal inflammation and fibrosis appears to be more intense [8-10].

The use of highly active antiretroviral therapy (HAART) for HIV has resulted in a significant decline in mortality, since

Received on 30 November 2005; revised 11 February 2006.

Address for correspondence: Dr. Eduardo Lorens Braga. Av. São Rafael 2152, Hospital São Rafael, São Marcos. CEP: 41256-900. Salvador, Bahia, Brazil. Phone:55-71-3399-6552/ 55-71-9988-1532 /Fax 55-71-3281-6552. Email: elbraga@ig.com.br

The Brazilian Journal of Infectious Diseases 2006;10(1):17-21. (C) 2006 by The Brazilian Journal of Infectious Diseases and Contexto Publishing. All rights reserved. it prevents opportunist infections and neoplasms related to the immunosuppressive state. On the other hand, mortality from end-stage liver disease by HCV is increasing in the coinfected population, due to faster progression to cirrhosis, liver insufficiency and hepatocellular carcinoma [11]. Liver toxicity due to HAART is increased by HCV, which can contribute to greater liver damage and an unfavorable outcome of the liver disease [12.13]. We examined the severity of liver disease in HCV-HIV co-infected patients compared to monoinfected HCV patients, and we investigated the clinicalepidemiological features associated with co-infection.

\section{Material and Methods}

Selection of patients. From January 2002 to June 2003, 134 individuals with chronic hepatitis C, aged between 18 and 75 years, were eligible for our study. They had to be seropositive for HCV-RNA, based on a reverse transcriptase-polymerase chain reaction (RT-PCR) test and also had to be tested for HIV-1 by enzyme immunoassay at study entry. Patients with the following characteristics were excluded: chronic liver disease from other etiologies, hepatitis B virus (HBV) coinfection, ethanol abuse, pre-existing psychiatric conditions, seizure disorders, opportunistic infections and other serious medical conditions. 
This study was approved by the institutional ethics review board, according to the Declaration of Helsinki. All patients participated voluntarily, were not remunerated, and they provided written informed consent before entering the study.

Study design. This was a sectional study, in which the patients were included prospectively. It was conducted by the Division of Gastroenterology and Hepatology of the Universidade Federal da Bahia, Hospital Universitário Edgard Santos, BahiaBrazil. On satisfying all eligibility criteria, patients were allocated to two different groups:

Group A-Sixty-nine patients co-infected by HIV and HCV

Group B - Sixty-four patients mono-infected by HCV.

At baseline, the following data were collected from patients: age, gender, risk group for HIV-HCV infection, use of medications, occurrence of symptoms-signs related to hepatic disease, liver enzymes profile, qualitative RNA-HCV with viral genotyping, $\mathrm{HIV}$ viral load, $\mathrm{CD}_{4}$ and $\mathrm{CD}_{8}$ counts. Intensity of liver disease was assessed using the ChildTurcotte-Pugh 5-15 score: < 7 Child A (compensated liver disease), between 7 and 9, Child B (significant liver dysfunction) and $>9$, Child C (decompensated liver disease). All patients were subjected to abdominal ultrasound, with description of the liver, spleen, and portal vein and a search for findings consistent with chronic liver disease. Patients with increased alanine aminotransferase (ALT) levels had a liver biopsy to assess necroinflamatory activity and fibrosis, unless there was decompensated liver disease with a prolonged prothrombin time. The METAVIR score system was used to determine hepatic histology according to necroinflamatory activity and fibrosis stage. Specimens were graded for the degree of activity using a four-level grading system based on the presence and severity of piecemeal necrosis, lobular necrosis and portal inflammation. Fibrosis stage was assessed through a four-level staging system, based on the presence of portal fibrosis, with or without septa and cirrhosis.

Statistical analysis. Continuous variables were expressed as mean \pm standard deviation and were compared using the Mann-Whitney test or the student-t test. Categorical variables were expressed as proportions, compared using the chi-square test or Fisher exact test to evaluate differences between proportions. Data were analyzed with SPSS (Statistical Package for Social Sciences) program version 10.0; p values $<0.05$ were considered statistically significant.

\section{Results}

Table 1 gives demographic data of the studied population. Ninety-seven (72.4\%) out of the 134 patients were male and 37 (27.6\%), female. Mean age was $42.4 \pm 9.1$ years (range). Sixtyfive (48.5\%) patients were co-infected with HCV-HIV and comprised group A; 69 (51.5\%) were mono-infected with HCV and comprised group B. Sixty (44.8\%) individuals were users of injectable drugs, 46 (34.3\%) had a previous diagnosis of a sexually transmitted disease (STD), 41 (30.6\%) had a history of sexual activity with persons of the same sex and 37 (27.6\%) had already been blood transfused. One-hundred-twenty (89.6\%) were scored as Child A (compensated liver disease) and 14 (10.4\%) Child B or C (decompensated liver disease). Thirty-four (25.4\%) individuals had a liver ultrasound suggestive of chronic liver disease. Anti-HBs was detectable in the serum of 51 (38.1\%) patients. Fifty (76.9\%) out of 65 individuals of group A were using antiretrovirus drugs (Table 1).

We found a significant difference in the use of illicit drugs between co-infected HCV/HIV subjects (group A) compared with mono-infected HCV individuals (group B), $\left(\chi^{2}=17.1\right.$; $\mathrm{p}<0.00004)$. Among 60 drug-addicted individuals, 41 (68.3\%) were co-infected HCV/HIV, versus 19 (27.3\%) mono-infected $\mathrm{HCV}$. There was also an association between previous history of STD and the co-infection group. Forty-six subjects had a previous diagnosis of STD: 34 (73.9\%) group A and 12 (20.1\%) group $\mathrm{B}\left(\chi^{2}=18.1 ; \mathrm{p}<0.00003\right)$. Detection of anti-HBs in serum was more prevalent in group A: 34 (66.7\%) out of 51 anti-HBs positive individuals were co-infected HCV/HIV. Thirty-two (78\%) out of 41 bi-homosexual subjects were co-infected HCV/ HIV versus 9 (22\%) mono-infected HCV $\left(\chi^{2}=20.6\right.$; $\left.p<0.000006\right)$. Decompensated liver disease was more frequently found in co-infected HCV/HIV subjects: 10 (71.4\%) out of 14 patients with decompensated liver disease (Child $\mathrm{B}$ or $\mathrm{C}$ ) were in group $\mathrm{A}$, versus four (29.6\%) in group $\mathrm{B}\left(\chi^{2}=3.29 ; \mathrm{p}=0.07\right.$, Table 2$)$.

Genotyping distribution and relation to different variables are shown in Table 3: 95 (70.8\%) patients were genotype-1 and 39 (29.2\%) genotype 2 or 3 . Genotypes $2-3$ were more prevalent in co-infected individuals than in the mono-infected HCV group (36.9\% versus $21.8 \%$, respectively; $\mathrm{p}<0.05$, and they were also more common in those who had been previously transfused with blood components. There was no association between HCV genotype and injectable drug use, diagnosis of an STD, sexual activity, ultrasound findings or result of anti-HBs (Table 3).

Ultrasound findings of chronic liver disease were more prevalent in individuals with advanced disease (Child B or C score): $10 / 14$ (71.4\%) ( $\left.\dot{\circ}^{2}=14.9 ; \mathrm{P}<0.0002\right)$, and in co-infected patients, when compared to mono-infected ones, respectively, 25/65 (38.5\%) and 9/69 (13\%): $\left(\div^{2}=11.4 ; \mathrm{P}<0.0008\right)$. In the bisexual-homosexual group of individuals a higher frequency of ultrasound findings of chronic liver disease was found, when compared to the heterosexual population enrolled in the study: $15 / 41$ (36.6\%) versus 19/93 (20.4\%): $\left(\dot{\div}^{2}=3.9 ; \mathrm{P}<0.05\right)$.

Fifty-three patients with elevated levels of ALT had a liver biopsy. Histological findings were stratified using the METAVIR score. Nine out of 21 (42.9\%) co-infected patients compared nine out of 32 (28.1\%) mono-infected individuals had histological evidence of moderate or intense necroinflammatory activity. Ten out of 21 (47.6\%) co-infected patients had moderate or intense fibrosis and 3 (14.3\%) had 
Table 1. Characteristics of the patients infected with hepatitis $C$ virus and human immunodeficiency virus

\begin{tabular}{|c|c|c|c|}
\hline Parameter & $\begin{array}{l}\text { Median } \\
\text { ( } \pm \text { range) }\end{array}$ & $\mathbf{N}$ & $\%$ \\
\hline$\overline{\text { Gender M / F }}$ & & $97 / 37$ & $72.4 / 27.6$ \\
\hline Age & $42.4( \pm 9.1)$ & 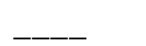 & \\
\hline $\begin{array}{l}\text { Co-infection / } \\
\text { mono-infection }\end{array}$ & & $65 / 69$ & $48.5 / 51.5$ \\
\hline Intravenous drug use & & & \\
\hline yes / no & & $60 / 74$ & $44.8 / 55.2$ \\
\hline STD & & & \\
\hline $\begin{array}{l}\text { yes / no } \\
\text { Sexual behavior }\end{array}$ & & $46 / 88$ & 34.3/65.7 \\
\hline Hetero/bi/homo & & $93 / 25 / 16$ & 69.4/18.7/11.9 \\
\hline $\begin{array}{l}\text { Hemotransfusion } \\
\text { yes/no }\end{array}$ & & $37 / 97$ & 27.6/72.4 \\
\hline $\begin{array}{l}\text { Stage of liver disease } \\
\text { child-Turcotte- }\end{array}$ & & & \\
\hline $\begin{array}{l}\text { Pugh A/B/C } \\
\text { USG }\end{array}$ & & $120 / 10 / 4$ & 89.6/7.4/3.0 \\
\hline $\begin{array}{l}\text { normal/abnormal } \\
\text { Anti-HBs }\end{array}$ & & $100 / 34$ & $74.6 / 25.4$ \\
\hline positive/negative & & $51 / 83$ & 38.1/61.9 \\
\hline
\end{tabular}

M: male; F: female; STD: sexually transmitted disease; hetero: heterosexual; bi: bisexual; homo: homosexual; USG: liver ultrasound; Anti-HBs: anti-hepatitis B antibodies.

Table 3. Relation between hepatitis C virus genotypes and other parameters

\begin{tabular}{lllll}
\hline Parameter & $\begin{array}{l}\text { G-1 } \\
\mathbf{n}(\%)\end{array}$ & $\begin{array}{l}\text { G-2/3 } \\
\mathbf{n}(\%)\end{array}$ & $\begin{array}{l}\text { Total } \\
\mathbf{n}(\%)\end{array}$ & $\mathbf{p}$ \\
\hline $\begin{array}{l}\text { Co-infection } \\
\text { (group A) }\end{array}$ & $41(63.1)$ & $24(36.9)$ & $65(48.5)$ & $<0,05$ \\
$\begin{array}{l}\text { Mono-infection } \\
\text { (group B) }\end{array}$ & $54(78.2)$ & $15(21.8)$ & $69(51.5)$ & \\
$\begin{array}{l}\text { Total } \\
\text { Hemotransfusion } \\
\text { yes }\end{array}$ & $95(70.8)$ & $39(29.2)$ & $134(100.0)$ & \\
no & $21(56.8)$ & $16(43.2)$ & $37(27.6)$ & $<0,05$ \\
G=genotypes. & $72(74.2)$ & $25(25.8)$ & $97(72.4)$ & \\
& & & &
\end{tabular}

cirrhosis, compared to 15 out of 32 (46.9\%) with moderate or intense fibrosis and three (9.3\%) with cirrhosis among monoinfected individuals. None of these differences were significant, which could be due to the small number of biopsies available.

Among the $65 \mathrm{HIV}$-positive subjects (group A), lymphocyte counts of $\mathrm{CD}_{4}<200$ were detected in 14 (21.5\%) and $\mathrm{CD}_{4}>200$ in 51 (78.5\%). We could not find a relationship between $\mathrm{CD}_{4}$ count and HCV genotype, Child score, ultrasound findings or intensity of hepatic inflammation/fibrosis. Similarly, there was no significant relation between HIV viral load and these variables.
Table 2. Comparison between co-infected and mono-infected (HIV/Hepatitis C) patients

\begin{tabular}{|c|c|c|c|c|}
\hline Parameter & $\begin{array}{l}\text { Co-infected } \\
\text { (group A) } \\
\text { n (\%) }\end{array}$ & $\begin{array}{l}\text { Mono- } \\
\text { infected } \\
\text { (group B) } \\
\text { n (\%) }\end{array}$ & $\begin{array}{l}\text { Total } \\
\text { n (\%) }\end{array}$ & $\mathbf{p}$ \\
\hline \multicolumn{5}{|l|}{ Gender } \\
\hline male & $48(49.5)$ & $49(50.5)$ & $97(72.4)$ & \multirow[t]{2}{*}{$>0,71$} \\
\hline female & $17(45.9)$ & $20(54.1)$ & $37(27.6)$ & \\
\hline $\begin{array}{l}\text { Age (median } \\
\pm \text { range) }\end{array}$ & $39.9 \pm 7.3$ & $44.7 \pm 10.1$ & - & $<0,003$ \\
\hline \multicolumn{5}{|c|}{ Intravenous drug use } \\
\hline yes & $41(68.3)$ & $19(31.7)$ & $60(44.8)$ & \multirow[t]{2}{*}{$<0,00004$} \\
\hline no & $24(32.4)$ & $50(67.6)$ & $74(55.2)$ & \\
\hline \multicolumn{5}{|l|}{ STD } \\
\hline yes & $34(73.9)$ & $12(26.1)$ & $46(34.3)$ & \multirow[t]{2}{*}{$<0,00003$} \\
\hline no & $31(35.2)$ & $57(64.8)$ & $88(65.7)$ & \\
\hline \multicolumn{5}{|l|}{ Anti-HBs } \\
\hline positive & $34(66.7)$ & $17(33.3)$ & $51(38.1)$ & \multirow[t]{2}{*}{$<0,001$} \\
\hline negative & $31(37.3)$ & $52(62.7)$ & 83(61.9) & \\
\hline \multicolumn{5}{|c|}{ Sexual behavior } \\
\hline bi./homo. & $32(78.0)$ & $9(22.0)$ & 41(30.6) & \multirow[t]{2}{*}{$<0,000006$} \\
\hline het. & $33(35.5)$ & $60(64.5)$ & $93(69.4)$ & \\
\hline \multicolumn{5}{|c|}{ Child-Pugh score } \\
\hline A & $55(45.8)$ & $65(54.2)$ & $120(89.6)$ & \multirow[t]{2}{*}{$=0,07$} \\
\hline $\mathrm{B}$ e C & $10(71.4)$ & $4(28.6)$ & $14(10.4)$ & \\
\hline
\end{tabular}

STD: sexually transmitted disease; anti-HBS: antibody against surface antigens of hepatitis B virus; bi=bisexual; homo=homosexual; het=herosexual.

Table 4. Relation between ultrasound findings and other parameters in HIV/Hepatitis C patients

\begin{tabular}{lllll}
\hline Parameter & $\begin{array}{l}\text { USG: N } \\
\text { n (\%) }\end{array}$ & $\begin{array}{l}\text { USG: CLD } \\
\text { n (\%) }\end{array}$ & $\begin{array}{l}\text { Total } \\
\mathbf{n ~ ( \% ) ~}\end{array}$ & $\mathbf{p}$ \\
\hline \multicolumn{2}{c}{ Child-Pugh score } & & & \\
A & $96(80)$ & $24(20)$ & $120(89.6)$ & $<0,0002$ \\
B e C & $4(28.6)$ & $10(71.4)$ & $14(10.4)$ & \\
$\begin{array}{l}\text { Population } \\
\text { co-infection }\end{array}$ & $40(61.5)$ & $25(38.5)$ & $65(48.5)$ & $<0,05$ \\
$\begin{array}{l}\text { mono-infect. } \\
\text { Sexual behavor }\end{array}$ & $60(86.9)$ & $9(13.1)$ & $69(51.5)$ & \\
$\begin{array}{l}\text { bi./homo. } \\
\text { het. }\end{array}$ & 26(63.4) & $15(36.6)$ & $41(30.6)$ & $<0,0008$ \\
\hline
\end{tabular}

USG: liver ultrasound; $\mathrm{N}=$ normal; $\mathrm{CLD}=$ chronic liver disease; bi=bisexual; homo=homosexual; het=herosexual.

\section{Discussion}

Survival of individuals infected with HIV has dramatically improved with HAART; however, chronic hepatitis C has 
emerged as a significant health concern in this population. Studies in Spain [7], Italy [14] and the USA [11] have confirmed a negative impact of co-infection on HCV-induced liver disease, with a higher incidence of decompensated cirrhosis and hepatocellular carcinoma.

We have described here the clinical and epidemiological features of co-infected HIV/HCV patients in the city of Salvador-Bahia-Brazil and also the intensity of liver disease in this population. A group of monoinfected HCV individuals was used for comparison. One limitation of our study is that it was not possible to determine the duration of HCV infection, since acute infection is asymptomatic in most cases. Clinical evaluation of the two groups in the population enrolled in the study (group A - coinfected and group B - monoinfected) was done during the same period of time at the Hepatology Service of the Brazilian Federal University Hospital in Salvador. A diagnosis of HCV infection was more frequent in males (73.8\% group A versus $71.0 \%$ group $B$ ) in the fourth decade of life (44.7 years group A versus 39.9 years group B). Similar findings were reported in a study with a cohort of 1,700 individuals infected by HIV, in which the median age of coinfected individuals was 40 years; the prevalence of HCV in this population was $16.1 \%$ [14].

The prevalence of HCV infection in HIV-positive individuals varies widely, from 7 to $98 \%$, depending mainly on the mode of transmission. In a large French cohort of 1,395 HIV-positive individuals, coinfection by HCV was $91 \%$ in injected drug users, $71 \%$ in recipients of blood transfusion and $7.3 \%$ in those who had sexually transmitted HIV [16]. Various studies have confirmed that drug use is the most important risk factor for coinfection. In our study, injected drug use was more frequently found in co-infected subjects: $63.1 \%$ versus $27.5 \%$ in monoinfected individuals, suggesting that parenteral transmission of HCV is more common than sexual transmission. Previous STD was common among coinfected patients (73.1\%) but not in monoinfected ones (26.9\%). Mohsen et al., in an epidemiological study, found an increased frequency of HCV infection among HIV-positive individuals, particularly in drug users [17].

In our study, HCV genotype- 1 was encountered in $70.8 \%$ of the infected subjects and $29.2 \%$ were genotype-2 or 3 , which is similar to what we found for seroprevalence of HCV genotype in the city of Salvador, Bahia, Brazil: $70 \% \mathrm{HCV}$ genotype- 1 versus $30 \%$ genotypes- 2 or 3 [18]. In the statistical analysis, genotypes 2 and 3 were considered together, as they have the same clinical significance and similar therapeutic response (genotype-2 was found in just two individuals of our patient population). Genotype-2/3 was more common among coinfected than in monoinfected individuals: $36.9 \%$ versus $21.8 \%$, respectively, as has also been reported by other authors [21].

Previous reports have consistently demonstrated that HIV accelerates the progression of HCV-related liver disease [19,22]. In a multicenter study [23], 547 individuals infected by HCV, among which $21 \%$ were coinfected by HIV, were prospectively followed. During a period of 10 years, cirrhosis was significantly more common in the coinfected group $(15 \%$ versus 3\%). Another investigation, on a cohort of 4,000 subjects with hemophilia, concluded that the risk of death caused by end-stage liver disease was five times superior in patients coinfected with HIV and HCV than in those monoinfected by HCV [24].

We evaluated liver disease severity, using clinical, laboratorial, radiological and histological features. Most patients (89.6\%) had compensated liver disease (Child A). Among those with decompensated cirrhosis (Child B or C), $79.4 \%$ were coinfected patients and $29.6 \%$ were monoinfected. We also observed a higher prevalence of patients with decompensated liver disease in the coinfection group than in the monoinfection one (15.5\% versus $5.8 \%$ ). However, these findings, were not statistically significance, although there was a trend $(\mathrm{p}=0.07)$. Ultrasound findings of chronic liver disease were more frequently found in the coinfected than in the monoinfected group (38.4\% versus $13.1 \%$, respectively, $\mathrm{p}<0.0007$ ). None of our patients had a diagnosis of hepatocellular carcinoma, though the risk apparently is higher in the coinfected population, when compared to HCV monoinfected patients.

It was clear that HIV-infected individuals with chronic hepatitis $\mathrm{C}$ develop necroinflamatory liver alterations more rapidly and have accelerated fibrogenesis [8]. In a clinical investigation that analyzed the histological activity index in 59 patients with positive HCV-RNA, higher levels of hepatic necrosis and fibrosis were found in coinfected individuals (all had a $\mathrm{CD}_{4}$ count above $200 / \mathrm{mL}$ ), than in negative subjects [9]. Findings of $\mathrm{CD}_{4}$ levels below $200 / \mathrm{mL}$ are associated with more advanced stages of liver fibrosis [25].

Fifty-three consenting patients with elevated levels of ALT underwent percutaneous liver biopsy. Hepatocellular necroinflamatory alterations were more frequently found in co-infected than in monoinfected individuals $(28.1 \%$ versus $4.2 \%$ ) and cirrhosis was also more common ( $15 \%$ versus $9.4 \%$ ). Probably because of the small sample size, these findings were not statistically significant.

Hepatitis B can work as a co-factor to progression to cirrhosis in patients with any chronic liver disease. It is important for the HIV population to seek vaccination against hepatitis B, due to the fact that liver disease has emerged as a leading cause of death among these individuals, particularly when they are coinfected with HCV. Of the 134 individuals enrolled in our study, 51 (38.1\%) were positive for anti-HBs; therefore, most of our patients were at risk for this infection. Some reports show a poor response rate to HBV vaccination in HIV individuals, particularly in patients with $\mathrm{CD}_{4}^{+} \mathrm{T}$-cell counts below 200. One limitation of our study is that it was not possible to determine the prevalence of individuals vaccinated against HBV. Among the co-infected population in our study, 34 (52.3\%) had a positive anti-HBs, compared to 
17 (24.6\%) in the mono-infected individuals. We think that this can be explained as a result of shared sexual transmission routes, and also because more co-infected patients had already been vaccinated against HBV. More investigations are necessary to confirm and explain these findings.

Chronic hepatitis C is an independent risk factor for antiretroviral-related hepatotoxicity. Various mechanisms of liver damage have been described, including a direct effect on P450 cytochrome by protease inhibitors, mitochondrial damage by nucleoside analogs and immunological restoration. We did not observe clinical or histological evidence of high degrees of hepatocyte injury among those using antiretroviral therapy. However, our investigation was not designed to answer this important question.

In conclusion, this observational study shows that coinfection with HIV and HCV is related to more advanced stages of HCV liver disease. Injected drug use and HCV genotype 23 were more frequently found among co-infected individuals. Finally, given that HBV hepatitis can contribute to progression to cirrhosis, we found that many patients were without the protective antibody, anti-HBs, which means they were not immunized against HBV. More studies of the Brazilian population that address some important questions concerning HCV-HIV co-infection are needed.

\section{References}

1. World Health Organization. Hepatitis C: Global Update. Weekly Epidemiologic Report 1997;72:341-4.

2. Thomas D.L. HCV and HIV. Conference at American Association for the Study of Liver Diseases - Postgraduate Course; 2000.

3. Wasley A, Alter M. Epidemiology of hepatitis C: geographic differences and temporal trends. Semin Liver Dis 2000; 20:116.

4. Sulkowsky M.S., Mast E.E., Sheef L.B., et al. Hepatitis C virus infection as an opportunistic disease in persons infected with human immunodeficiency virus. Clin Infect Dis 2000;30:77-84.

5. Serfaty L., Chazouilleres O., Poujol-Robert A., et al. Risk factots for cirrhosis in patients with chronic hepatitis $\mathrm{C}$ virus infection: results of a case-control study. Hepatology 1997;6:776-9.

6. Poynard T., Bedossa P., Opolon P. Natural history of liver fibrosis progression in patients with chronic hepatitis C. Lancet 1997;349:825-32.

7. Soriano V., Garcia-Samaniego J., Rodriguez-Rosado R., et al. Hepatitis C and HIV infection: biological, clinical, and therapeutic implications. J Hepatol 1999;31:119-23.

8. Allory Y., Charlotte F., Benhamou Y., et al. Impact of human immunodeficiency virus infection on the histological features of chronic hepatitis C: A case-control study. The Multiviric Group. Hum Pathol 2000;31:69.

9. Garcia-Samaniego J., Soriano V., Castilla J., et al. Influence of hepatitis $\mathrm{C}$ virus genotypes and HIV infection on histological severity of chronic hepatitis C. The Hepatitis/ HIV Spanish Study Group. Am J Gastroenterol 1997;92:1130-4.
10. Bierhoff E., Fischer H.P., Willsch E., et al. Liver histopathology in patients with concurrent chronic hepatits C and HIV infection. Virshows Archives 1997;430:271.

11. Bica J., McGovern B., Dhar R., et al. Increasing mortality due to end stage liver disease in patitents with human immunodeficiency virus infection. Clin Infect Dis 2001;32:492-7.

12. Sulkowski M.S., Thomas D.L., Chaisson R.E., Moore R.D. Hepatotoxicity associated with antiretroviral therapy in adults infected with human immunodeficiency virus and the role of hepatitis C or B virus infection. JAMA 2000;283:74-80.

13. Soriano V., Garcia-Samaniego J., Valencia E., et al. Impact of chronic viral liver disease due to hepatitis viruses as cause of hospital admission and death in HIV infected drug users. Eur J Epidemiol 1999;15:1-4.

14. Di Perri G., Raiteri R., Bonora S., et al. Liver failure from HCV as the current leading cause of death in HIV-infected patients in northern Italy. In: Program and abstracts: $8^{\text {th }}$ CROI 2001;573A.

15. Sulkowski M.S., Thomas D.L. Hepatitis C in the HIV infected person. Ann Intern Med 2003;138:197-207.

16. Saillour F., Dabis F., Dupon M., et al. Prevalence and determinants of antibodies to hepatitis $\mathrm{C}$ virus and markers for hepatitis B virus infection in patients with HIV infection in Aquitaine. Groupe d'Epidemiologie Clinique du SIDA en Aquitaine. Br Med J 1996;313:461-4.

17. Mohsen A.H., Trent HCV study group. The epidemiology of hepatitis $\mathrm{C}$ in a UK regional population of 5.12 million. Gut 2001; $5: 707-13$.

18. Silva L., Parana R., Sousa S., et al. Hepatitis $C$ virus genotypes in a northeastern area of Brazil. The American Journal of Tropical Medicine and Hygiene 2000;62:257-60.

19. Zeuzem S., Franke A., Lee J., et al. Phylogenetic analysis of hepatitis $\mathrm{C}$ virus isolates and their correlation to viraemia, liver function tests and histology. Hepatology 1996;43:10039.

20. Pol S., Lamorthe B., Thi N.T., et al. Retrospective analysis of the impact of HIV infection and alcohol use on chronic hepatitis C in a large cohort of users. J Hepatol 1998;945:28.

21. Staples C.T., Jr. Rimbland D., Dudas D., et al. Hepatitis C in the HIV (human immunodeficiency virus) Atlanta V.A. (Veterans Affairs Medical Center) Cohort Study (HAVACS): the effect of coinfection on survival. Clin Infect Dis 1999;29: 150-4.

22. Benhamou Y., Bochet M., Di M. Charlotte, et al. Liver fibrosis progression in human immunodeficiency virus and hepatitis C virus coinfected patients. The Multiviric Group. Hepatology 1999;30:1054-8.

23. Soto B., Sanchez-Quijano A., Rodrigo L., et al. Human I immunodeficiency virus infection modifies the natural history of chronic parenterally acquired hepatitis $C$ with an unusually rapid progression to cirrhosis. J Hepatol 1997;26:1-5.

24. Darby S., Ewart D., Giagrande P., et al. Mortality from liver cancer and liver disease in hemophiliac men and boys in UK given blood products contaminated with hepatitis C. Lancet 1997;350:1425-31.

25. Puoti M., Bonacini M., Spinetti A., et al. Liver fibrosis progression as related to CD4 cell depletion in patients coinfected with hepatitis $\mathrm{C}$ virus and human immunodeficiency virus. J Infect Dis 2001;183:134-7. 